\title{
Design and Numerical Analysis of Optimized Planetary Gear Box
}

\author{
S.B.Nandeppagoudar ${ }^{1,2}$, S.N.Shaikh ${ }^{1}$, S. R. Gote ${ }^{1}$, S. P. More ${ }^{1}$, \\ A. S. Chaudhari ${ }^{1}$, N. R. Borse ${ }^{1}$, S.H.Gawande ${ }^{1}$ \\ ${ }^{I}$ (Department of Mechanical Engineering, M.E.S. College of Engineering, Pune, S.P. Pune University, India) \\ ${ }^{2}$ (Managing Director, Naveen Hydro-controls, MIDC Bhosari, Pune, India)
}

\begin{abstract}
Planetary gears are very popular as a power transmission and extensively used in different industrial fields like automobiles, helicopters, aircraft engines, heavy machinery, and a variety of other applications to perform speed reduction due to several advantages over conventional parallel shaft gear systems. The advantages include compactness, high torque to weight ratios, reduced radial bending loads. Many researchers have worked to optimize the radial size of planetary gear box. In this paper 3stage planetary gear box is redesigned by reducing one stage which will be suitable for machine tool application where the space and load constrains is the prime objectives. Analytical and numerical results are compared to see the effectiveness of modified planetary gear box.
\end{abstract}

Keywords - Optimization, Planetary gear box (PGT), Tangential load,

\section{INTRODUCTION}

The planetary gear boxes have some advantages over normal gear boxes. Planetary gear boxes are more accurate and high precision due to their compactness. Planetary gear boxes have high efficiency and less power loss. Due to these features multi stage gear boxes are used for high power transmitting applications.

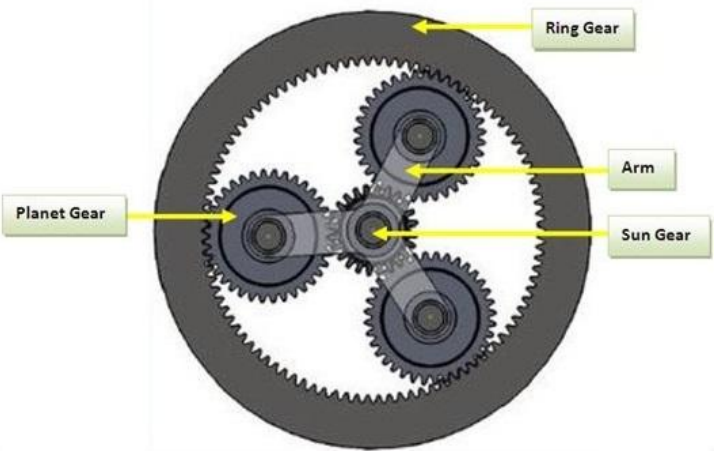

Fig.1. Basic layout planetary gear

Fig.1 shows basic layout of planetary gear set which consists of four different elements that produce a wide range of speed ratios in compact layout. These elements are, (1) Sun gear, an externally toothed ring gear co-axial with the gear train (2) Annulus, an internally toothed ring gear coaxial with the gear train (3) Planets, externally toothed gears which mesh with the sun and annulus, and (4) Planet Carrier, a support structure for planets, co-axial with the train. Planetary gear system as shown in Fig.1 is typically used to perform speed reduction due to several advantages over conventional parallel shaft gear systems. Planetary gears are also used to obtain high power density, large reduction in small volume, pure torsional reactions and multiple shafting. Another advantage of the planetary gearbox arrangement is load distribution. The more the planets in the system, the greater load ability and the higher the torque density. The PGT arrangement also creates greater stability due to the even distribution of mass and increased rotational stiffness.In today's scenario there is the need of light weight and compact gearbox design with high load carrying capacity and compact in size. So many researchers have worked to the size of planetary gear box. . L.Chang et.al. [1] studied the robust model stiffness of cylindrical gears \& pinions. He studied that reduced rim and web thickness results in smaller mesh stiffness Studies conducted by D.I.Syed [2] to optimize the design of the planetary gear trains based on the load analysis. One more researcher B-R.Hohn,.[3] worked on the lowering the weight of the planetary gear box. More the load factor required, more mesh load necessary; this will result in complexity in assembly of the planets with lower number of teeth.N..Marjanovic [4] studied practical approach to the optimization of planetary gear trains with spur gears. In his study he presented the selection of optimal gear trains and also selection of optimal position 6th National Conference RDME 2017, 17th- 18th March 2017. 
for shaft axes of gears trains with "spur gears". In this the volume of the planetary gear trains with "spur gears" is drastically reduced by $23 \%$ J. Stefanović [5] conducted study of planetary gear box optimization. He formulated objective function with optimization variables considering face width, gear modules and optimization function as volume, mass and manufacturing cost, efficiency. Study conducted by O. Bunga al. [6] in his study on mass optimization of design of two stage coaxial high speed reducer with GA (Genetic Algorithm) compared in the conventional design of gear reduction with optimized design by GA. He studied about the compromise between the service life and mass was presented \& they concluded and understood that the required service life needs to be sacrificed with some percentage (75\%) for a $2.5 \mathrm{~kg}$ saving (roughly $7 \%$ ).U. Kissling also did study on the same line on an optimization procedure used for complete planetary gear box with weight, cost, torque and dimensional restriction. After exhaustive literature survey it is seen that large amount of efforts have been put optimize the radial size of the gear box. It is seen that the efforts for reducing the axial length of the gear box keeping the load carrying capacity same gives very good vertical space reduction in existing gear for $\mathrm{CNC}$ bending machine tools and hence we have decided to conduct the research in this area.

\section{PROBLEM DEFINATION AND OBJECTIVE}

This work focuses on the planetary gear box used in the CNC bending machines where input torque and speed are generated by the servo-motor. Reduction ratio of 80-110 is required at the output shaft. Input parameters can be varied based on the specific requirement as servo motor is used in this system as a prime mover.Fig. 2 shows the configuration of existing gear box fitted on the CNC machine. There are three stages in this gear box and the reduction ratio is 4.8 at each stage. Table 1 shows the specification of 3 -stage existing gear box Total gear reduction ratio required is 110 .

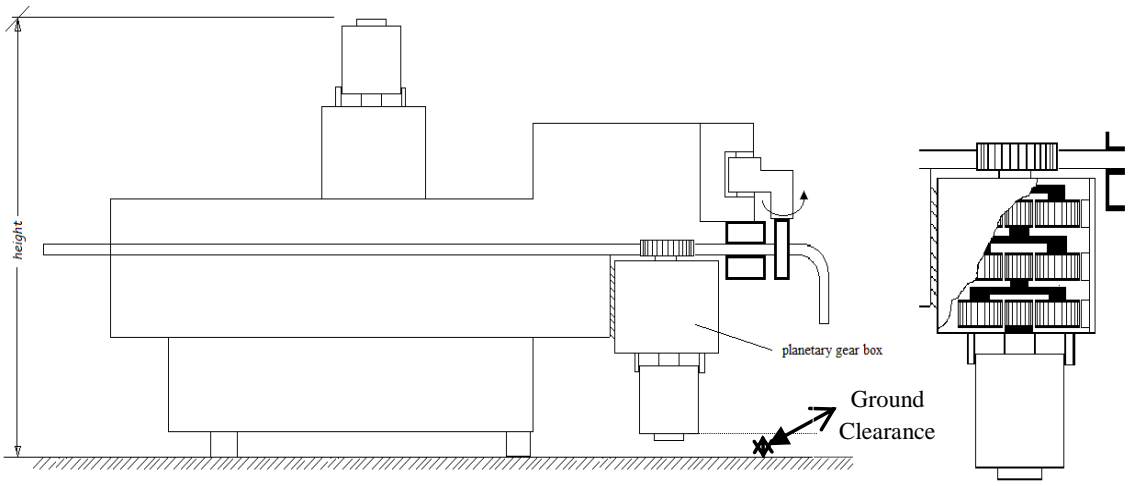

Fig.2. Present planetary Gear Box arrangement

Table 1. Existing Gear Box data

\begin{tabular}{|l|l|l|}
\hline Parameter & Symbol & Value \\
\hline Dia. of sun gear $(\mathrm{mm})$ & $\mathrm{Z}_{\mathrm{a}}$ & 20 \\
\hline Dia. of planet gear $(\mathrm{mm})$ & $\mathrm{Z}_{\mathrm{b}}$ & 28 \\
\hline Dia. of ring gear $(\mathrm{mm})$ & $\mathrm{Z}_{\mathrm{c}}$ & 76 \\
\hline No. of Planets & $\mathrm{N}$ & 3 \\
\hline
\end{tabular}

Present three stage gear box need more space as compared to proposed two stage gear box. As the number of stages increases in the planetary gear box, clearance of the gear box with ground decreases as shown in Figs.2, 3. The working conditions where the machine is installed and the gear box is closer to the ground, it becomes challenging to operate the machine in limited clearance with the ground (negative clearance). There are always chances of gear box fouling with the ground in existing machine tool. To overcome this challenge, in this work the number of stages in gear box are reduced to two without compromising on the output torque and the speed. Fig. 3 shows arrangement of proposed 2 stage planetary gear box. 


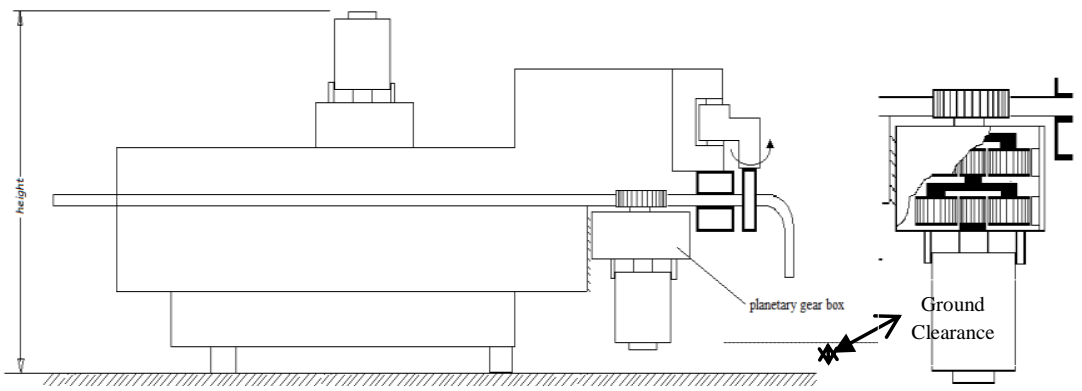

Fig.3. Proposed planetary gear box arrangement

\section{DESIGN OF PROPOSED PLANETARY GEAR BOX}

To convert a three stage gear box into two stage gear box; several facts are considered as follows.

- To achieve the total gear reduction between 80-110.

- The range of gear ratio is variable as input is provided by servo motor.

- The output torque shall be within the range of $1800-2000 \mathrm{Nm}$.

- The output speed shall be within the range of $2000 \mathrm{rpm}$ to $3000 \mathrm{rpm}$

The gear ratio to be attend in two stages of planetary gear box is 9.53 in each stage i.e. total gear reduction ratio is $i=i_{1} \times i_{2}=90.8$. In Table 2 configuration no. 7 is selected for our study which will give higher reduction ratio which we are looking for.

Table 2. Available configuration of the planetary gear system

\begin{tabular}{|l|l|l|l|l|l|l|l|}
\hline $\begin{array}{l}\text { Sr.N } \\
\text { o. }\end{array}$ & $\begin{array}{l}\text { No. of theeth } \\
\text { Sun Gear }\end{array}$ & $\begin{array}{l}\text { No. of teeth } \\
\text { Planet Gear }\end{array}$ & $\begin{array}{l}\text { No. of teeth } \\
\text { Ring Gear }\end{array}$ & $\begin{array}{l}\text { Gear ratio } \\
\text { in each } \\
\text { stage }\end{array}$ & $\begin{array}{l}\text { Overall } \\
\text { Reduction } \\
\text { ratio }\end{array}$ & $\begin{array}{l}\text { Check for } \\
\text { planet } \\
\text { equispacing }\end{array}$ & $\begin{array}{l}\text { Check } \\
\text { planet for } \\
\text { no. of teeth }\end{array}$ \\
\hline 1 & 16 & 53 & 122 & 8.63 & 74.5 & 46 & \\
\hline 2 & 16 & 56 & 128 & 9 & 81 & 48 & 53 \\
\hline 3 & 16 & 59 & 134 & 9.3 & 86.5 & 50 & 56 \\
\hline 4 & 17 & 55 & 127 & 8.5 & 72.25 & 48 & 59 \\
\hline 5 & 17 & 58 & 133 & 8.8 & 77.44 & 50 & 55 \\
\hline 6 & 17 & 61 & 139 & 9.18 & 84.3 & 52 & 58 \\
\hline $\mathbf{7}$ & $\mathbf{1 7}$ & $\mathbf{6 4}$ & $\mathbf{1 4 5}$ & $\mathbf{9 . 5 3}$ & $\mathbf{9 0 . 8}$ & $\mathbf{5 4}$ & 61 \\
\hline
\end{tabular}

3.1 Design by Analytical Approach: In this section design of proposed gear box explain in details.

- Given data :

$\mathrm{P}=5.8 \mathrm{~kW} ; \mathrm{N}_{1}=3000 \mathrm{RPM}, \mathrm{Da}=38 \mathrm{~mm}, \mathrm{Db}=132 \mathrm{~mm}, \mathrm{i}=9.53 / 1, \mathrm{Ba}=25 \mathrm{~mm}, \mathrm{Bb}=22 \mathrm{~mm}, \alpha=20^{\circ}$.

- Center Distance:

To find the center distance Eq. 1 is used

Center distance $=a=\frac{Z_{1}+Z_{2}}{2} \times m$

Center distance $=a=\frac{17+64}{2} \times 2=81$

$\mathrm{a}=81$

- Module Calculation: To find out the module of parallel axis gearing the Eq.2 is used. For Spur Gears a normal module is expressed as,

$$
m=\frac{2 \times a}{z_{1}+z_{2}}
$$

$m=\frac{2 \times 81}{17+64}=2$

where: 
a- Centre distance between gear axes,

$z_{1}, z_{2}$ numbers of teeth respectively for pinion (Sun gear) and gear (Planet gear).

- Transmission torque : The torque transmitted by the high speed shaft is given by:

$$
T_{\text {out }}=\frac{30 \times P}{\pi \times N_{1}} \times i \times k_{s}
$$

For first stage gear reducer with spur gears knowing servo motor power, $\mathrm{P}=5.8 \mathrm{~kW}$, rotational speed $\mathrm{N}_{1}=3000$ rpm and gear ratio $\mathrm{i}=9.53 / 1, \mathrm{~T}_{\mathrm{in}}=16 \mathrm{~N}-\mathrm{m}$

1. Load Service : uniform,

2. operating conditions at output: moderate shock,

3. Duty hours of Gear box: $t=10 \mathrm{hrs} /$ day.

Output torque of the reducer in stage 1 is given as,

$$
\begin{aligned}
T_{\text {out }} & =\frac{30 \times P}{\pi \times n_{m}} \times i \times k_{s} \\
T_{\text {out }} & =\frac{30 \times 5.8}{\pi \times 3000} \times 9.53 \times 1.25 \times 0.85 \\
T_{\text {out }} & =0.1869 \mathrm{kN}-\mathrm{m} \\
& =186.9 \mathrm{~N}-\mathrm{m}
\end{aligned}
$$

It is for one planet in a system, there are 3 planets therefore the total output torque in $1^{\text {st }}$ stage is 3 times $\mathrm{T}_{\text {out }}$

$$
\begin{aligned}
\text { TotalT }_{\text {out }} & =3 \times T_{\text {out }}=3 \times 0.1869=0.5608 \mathrm{kN}-\mathrm{m} \\
& =560.8 \mathrm{~N}-\mathrm{m}
\end{aligned}
$$

Let, $\mathrm{k}_{\mathrm{s}}$ is a service factor and

$$
\begin{array}{r}
k_{s}=k_{a} \times k_{t} \\
k_{s}=1.25 \times 0.85
\end{array}
$$

where:

$k_{a^{-}}$is an application factor and in accordance with the Table 2. It equals 1.25 for gear input operating conditions as uniform and output operating conditions as moderate shock.

$K_{t}$ is a duty factor for a running time of the reducer of $3 \mathrm{hrs} /$ day equals 0.85

Similarly for $2^{\text {nd }}$ stage the output torque can be calculated as follows.

Here we have considered two cases, one based on single planet transmission and other three planet transmission. For $2^{\text {nd }}$ stage gear reducer single planet with spur gears with servo motor power $\mathrm{P}=6.25 \mathrm{~kW}$, Rotational speed $\mathrm{N}_{12}=314.8 \mathrm{rpm}$, Gear ratio i $=9.53 / 1$.

$$
\begin{aligned}
T_{\text {out }} & =\frac{30 \times P}{\pi \times N_{12}} \times i \times k_{s} \\
T_{\text {out }} & =\frac{30 \times 6.25}{\pi \times 314.8} \times 9.53 \times 1.25 \times 0.85 \\
T_{\text {out }} & =1.919 \mathrm{kN}-\mathrm{m} \\
& =1919 \mathrm{~N}-\mathrm{m}
\end{aligned}
$$

- Spur pinion loads

Pressure angle equals $\alpha=20^{\circ}$. we know,

Tangential load,

$$
\begin{gathered}
W_{t 1}=W_{t 2}=\frac{9550000 \times P}{N_{1} \times(d / 2)} \\
W_{t 1}=W_{t 2}=\frac{9550000 \times 5}{3000 \times 17}=936 \\
=936 \mathrm{~N}
\end{gathered}
$$

Radial load, $W_{r}=W_{t} \times \tan 20^{\circ}$

$$
\begin{aligned}
W_{r} & =W_{t} \times \tan 20^{\circ}=936 \times 0.3639=340.8 \mathrm{~N} \\
& =340.8 \mathrm{~N}
\end{aligned}
$$




$$
\text { Total load, } \quad W=\frac{936}{\cos 20^{\circ}}=996 \mathrm{~N}
$$

\subsection{Design by Numerical Approach}

Numerical analysis is performed in Power Gear software of modified planetary gear box which is the best tool to find the fundamental specifications, various AGMA factors and manufacturing methods for Involutes Spur and Helical Gear and gearing system design. Figs. 4-5 shows the screen shots taken while doing numerical analysis for better understanding of the design methodology.

\section{Analysis Steps}

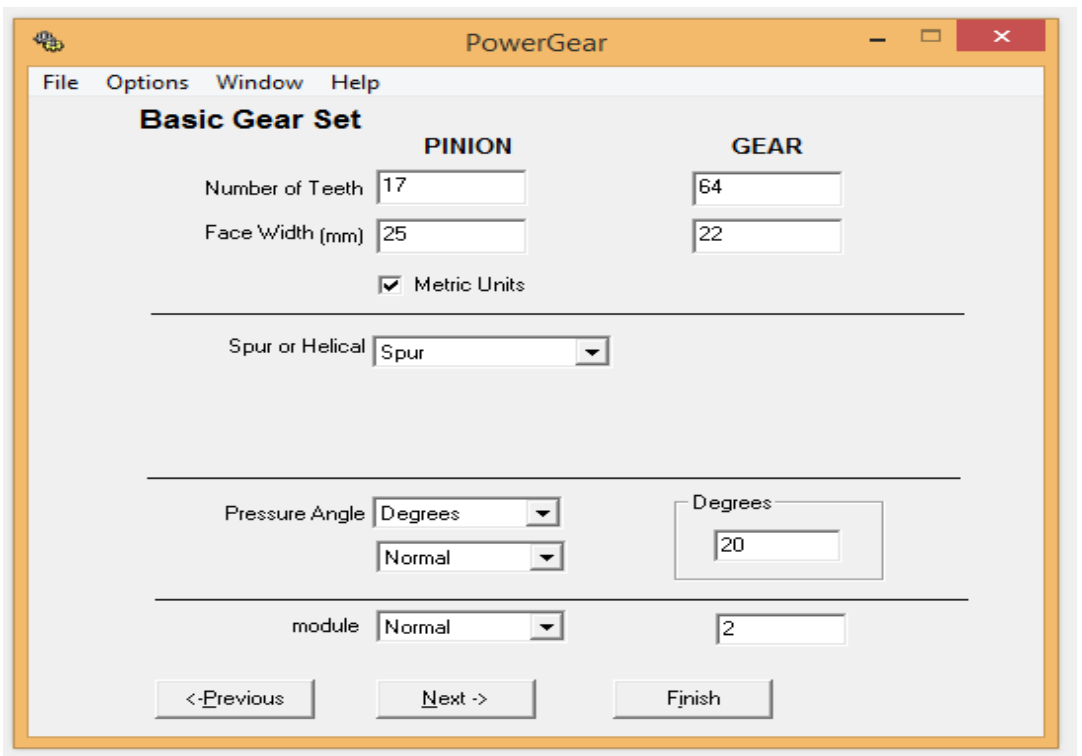

Fig.4. Step 1 basic gear input

In first stage calculation, the inputs as shown in Fig. 4 were entered to get the output as center distance as shown in Fig. 5. The output in the first step is the center distance of sun gear and planet gear which is equals to 81 .

By selecting "use standard center distance option" we can find in the next step addendum dedendum, fillet form selection and calculation screen will display as shown in next screen Fig 6. By selecting tip diameter in both cases and entering $38 \mathrm{~mm}$ and $132 \mathrm{~mm}$ we will get the screen Fig.6. Fig. 7 shows the data obtained by performing gear design by using Power Gear software. This data can be used for manufacturing proposed gear box.

\section{RESULTS AND DISCUSSION}

In this paper the three stage planetary gear box which is used in CNC bending machine is modified by reducing one stage to make it more compact. To compare the results of analytical work, numerical analysis is performed by using Power Gear software.Table. 3 shows results obtained by analytical and numerical approach. From Table 3 for estimated and simulated geometric parameters of gears the ooperational speed in $1^{\text {st }}$ stage and $2^{\text {nd }}$ stage remain same. Hence the design parameter obtained by both approaches shows very closed match.

Table3. Result comparison of analytical and numerical approach

\begin{tabular}{|l|l|l|l|}
\hline $\begin{array}{l}\text { Sr. } \\
\text { No. }\end{array}$ & Parameters to be compared & $\begin{array}{l}\text { Theoretical } \\
\text { Analysis }\end{array}$ & $\begin{array}{l}\text { Numerical } \\
\text { Analysis }\end{array}$ \\
\hline 1 & Operational speed in 1st Stage & $797.87 \mathrm{rpm}$ & 796.87 \\
\hline 2 & Operational speed in 2nd Stage & $83.7 \mathrm{rpm}$ & 83.7 \\
\hline 3 & Tangential Load & 936 & 936.2 \\
\hline
\end{tabular}




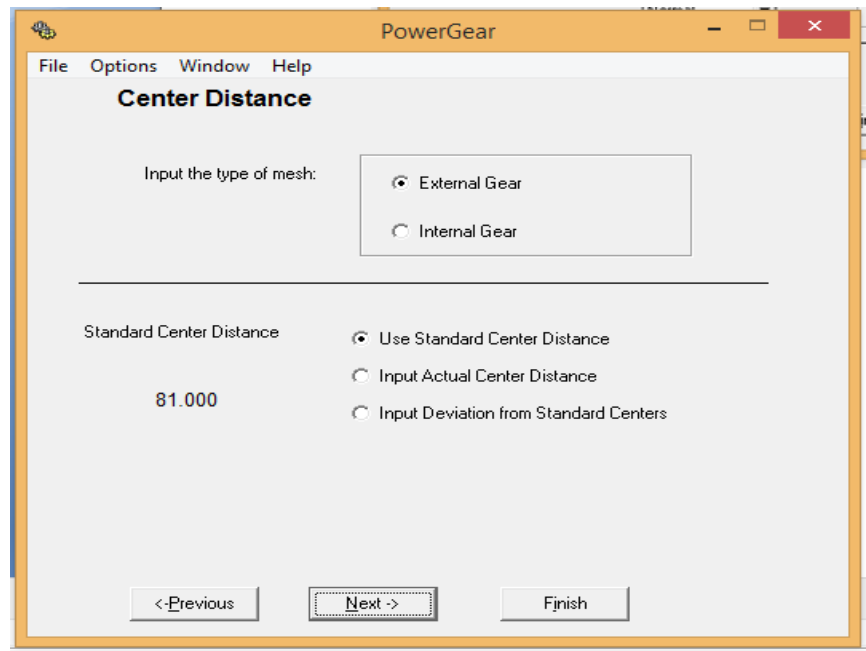

Fig.5. Step 2 Calculation of center distance

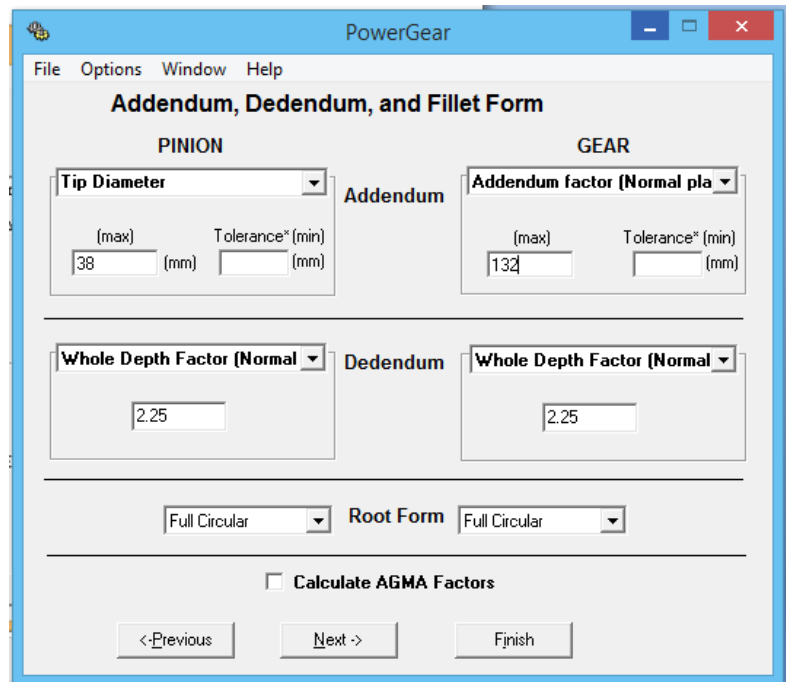

Fig. 6. Step 3 enter input tip diameter

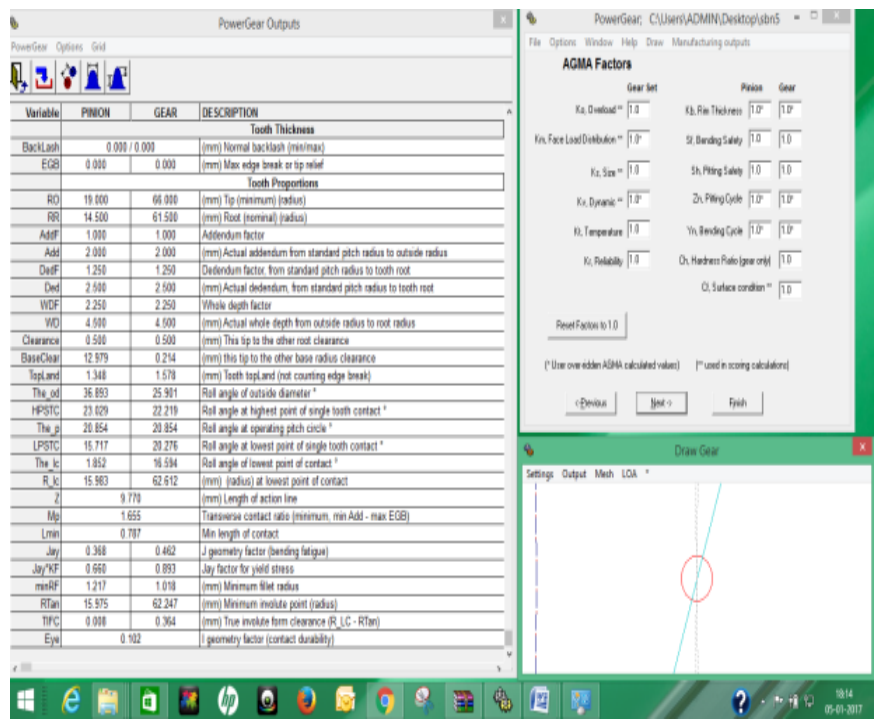

Fig.7. Step 4 Manufacturing data format 


\section{CONCLUSION}

The main objective of this work was to redesign the planetary gear box which will be suitable for machine tool application, where the space and load constrains were the prime objectives. In the modified gear box high reduction ratio 90.8 is achieved in 2 stages for planetary gears compared to 3 stage gear box. To check the effectiveness of modified 2 stage gear box and to compare results of analytical approach, nnumerical analysis is carried out by using Power Gear software. It is observed that results obtained by analytical and numerical methods are one and the same therefore the new designed gear box is the equivalent of existing three stage planetary gear box. Hence it is seen that the optimization of gear box for high reduction ratio and space reduction is satisfied.

\section{REFERENCES}

[1] L.Chang, G. Liu, Liyan Wu, - A robust model for determining the mesh stiffness of cylindrical gears, Mechanism and Machine Theory, 87,2015, 93-114 .

[2] D. Ibrahim Syed, Md. Abdul Raheem Junaidi,S.Nawazish Mehdi ,Design, Load Analysis and Optimization of Compound Epicyclic Gear Trains, American Journal of Engineering Research ISSN 2320-0936,2(10), 2013, 146153.

[3] B-R Höhn, K. Stahl ,P.Gwinner ,Light-Weight Design for Planetary Gear Transmissions, Gear Technology,2013,96103.

[4] N. Marjanovic, Biserka Isailovic, Vesna Marjanovic, Zoran Milojevic, Mirko Blagojevic, Milorad Bojic, -A practical approach to the optimization of gear trains with spur gears, Mechanism and Machine Theory, 53,2012,116

[5] J.Stefanović-Marinović ,Load Allocation and Equilibrium for Planetary Gear Reducers of Earth-Pressure-Balance Shield Machine, Journal of Mechanics Engineering and Automation 2,2012,365-373.

[6] O.Buiga, LTudose ,Optimal mass minimization design of a two-stage coaxial helical speed reducer with Genetic Algorithms, Advances in Engineering Software, 68, 2014,25-32. 